\title{
Study on Inventory Control Strategy of Beijing Fresh Produce Distribution Center
}

\author{
CUI Dongyu ${ }^{1, a, *}$ \\ ${ }^{1}$ School of Economics and Management of Beijing Jiaotong University, Beijing, China \\ a16120570@bjtu.edu.cn
}

Keywords: Fresh produce; inventory control; distribution center; deterioration rate

\begin{abstract}
The establishment of a distribution center provides a place for storage and processing of fresh produce, which directly affects the quality of fresh produce and food safety. The effective control of the inventory of fresh produce in the distribution center will help reduce the uncertainty of the supply of fresh produce in the actual operation and raise the service level in the upstream and downstream of the supply chain. It is the key to ensuring the daily food supply for community residents. This paper analyzes the current situation and existing problems of fresh produce inventory management in Beijing, and combines the perishable properties of fresh produce to construct an inventory control model of fresh produce in distribution center. And through the actual example, we can get the best order cycle and the optimal order quantity of fresh produce in distribution center. The research has certain reference value for improving the circulation efficiency of fresh produce in Beijing, and reducing the cost of agricultural products circulation and depletion.
\end{abstract}

\section{Introduction}

Beijing is a typical city for population consumption. In 2016, the total retail sales of consumer goods in Beijing was as high as 229.67 billion yuan. As far as Beijing is concerned, its low self-sufficiency ratio of agricultural products can hardly satisfy people's huge living needs. The vast majority of varieties rely on the supply of external markets, which places higher demands on the storage and safety of fresh produce. At the same time, in order to solve the problem of "the last kilometer of vegetable circulation", in 2013, Beijing vigorously developed the convenience food market and community vegetable market. Gradually formed a standardize the community food market, community restaurants and fresh supermarkets as an important complement, the network direct sales force for the new force, a variety of formats coexist, complement each other and common development. However, with the proposed strategy of dissolving Beijing's non-capital functions, a large number of agricultural product wholesale markets have been relocated. From the Xinfadi Wholesale Market and other primary wholesale markets to the low-level wholesale markets in the urban areas to the community vegetable markets, only a few licensed trucks can enter the Fourth Ring during the day. Moreover, due to problems such as inadequate primary processing and lack of cold chain transportation equipment, the loss of fresh agricultural products is very serious and can not meet the huge market demand for real-time replenishment during the day in the community of the Fourth Ring.

On the other hand, the existing agricultural product wholesale market only has the function of wholesale and transfer, the limited storage conditions and the lack of necessary cold chain facilities and equipment, which greatly increase the damage rate of agricultural products. In order to solve this situation, some cold chain company giants have established a distribution center on the basis of docking in the rural communities to give full play to their role in the collection and processing of warehousing. Strive to minimize the loss of products and coordinate the inventory levels of fresh agricultural products in the upstream and downstream, and provide guarantees for the normal supply of fresh food in the community market. According to the perishable nature of fresh produce, it has strong sensitivity to time and storage conditions. Effective inventory management of fresh agricultural products in the distribution center not only ensures the quality and safety of fresh produce, but also improves the circulation efficiency of fresh produce throughout Beijing. It has 
important practical significance.

\section{Study On The Management Of Fresh Agricultural Products In Beijing}

Beijing is the main sales area for fresh agricultural products. The production areas of agricultural products in Beijing are basically divided into suburban supply and external purchase. Among them, in the wholesale and retail sales, the supply is mainly from overseas procurement. And in chain supermarkets, the main supply in Beijing suburbs. Beijing's local supply to Beijing is within 20\%, and foreign supply accounts for over $80 \%$. At present, the circulation of fresh agricultural products in Beijing basically follows the traditional circulation mode of the wholesale market, that is, the wholesale market is the main place for the storage and transit of fresh produce in Beijing. With the increase in the demand and variety of fresh agricultural products, problems of traditional wholesale markets such as backward management, poorly-organized storage conditions, lack of cold chain facilities and equipment, high agricultural product damage rate, and low operating efficiency have become increasingly prominent. It is difficult to meet people's requirements for the quality of agricultural products.

In recent years, many scholars have conducted various researches on how to optimize the inventory of fresh foods. Sun, Dong et al. ${ }^{[1]-[2]}$ constructed a single-level inventory optimization model for perishable goods. Olsson F, Li Xiang et al. ${ }^{[3]-[4]}$ analyzed the secondary inventory model of perishable foods. To comply with the actual situation, Li Changbing, Wang Shuyun, Ran Wenxue, Hou Guodong, etc. ${ }^{[5]-[8]}$ took the fresh foods supply chain as the research object and constructed a multi-level inventory model for fresh food. On the other hand, more scholars have begun to pay attention to the effect of deteriorating rates on food inventory control. Deng Qi ${ }^{[9]}$ solved the perishable goods inventory model by taking into account the deterioration rate and the time factor to obtain the optimal order cycle and the optimal order quantity. Wang Daoping ${ }^{[10]}$ studied the problem of inventory optimization of perishable goods with the deterioration rate that obeys Weibull distribution. Han Shuguang ${ }^{[11]}$ used the freshness function to establish a metamorphic inventory model that takes into account the effects of freshness and transit time, and analyzed the order period and order quantity when the benefit of the supply chain is maximized. Research shows that effective inventory management can greatly reduce the loss of fresh produce, extend the shelf life of fresh produce, and increase its circulation efficiency.

\section{Research On The Inventory Control Of Fresh Produce Distribution Center In Beijing}

In order to ensure the daily food needs of the community, the distribution center will deliver fresh produce to the community market in real time based on actual needs. In addition to considering the application of cold chain technology storage to ensure food safety. How to effectively control the inventory of fresh produce in the distribution center is the key to realizing the timely supply of fresh produce in the community vegetable market, preventing shortage of goods, and responding to supply risks.

\subsection{The Composition and Characteristics of Fresh Produce Distribution Center Inventory}

Under the background of docking in rural communities, the circulation pattern of fresh agricultural products was transformed into the farmer- distribution center -community vegetable market (as shown in Fig.1). The role of the distribution center is mainly to centralize the raw agricultural products that are small-batch. And through centralized procurement and processing in distribution center to form bulk transport, thus providing the community food market with High-volume, high-efficiency and low-cost delivery services. Scilicet, the distribution center is the key to coordinating the production, inventory, distribution, and sales of fresh agricultural products. 

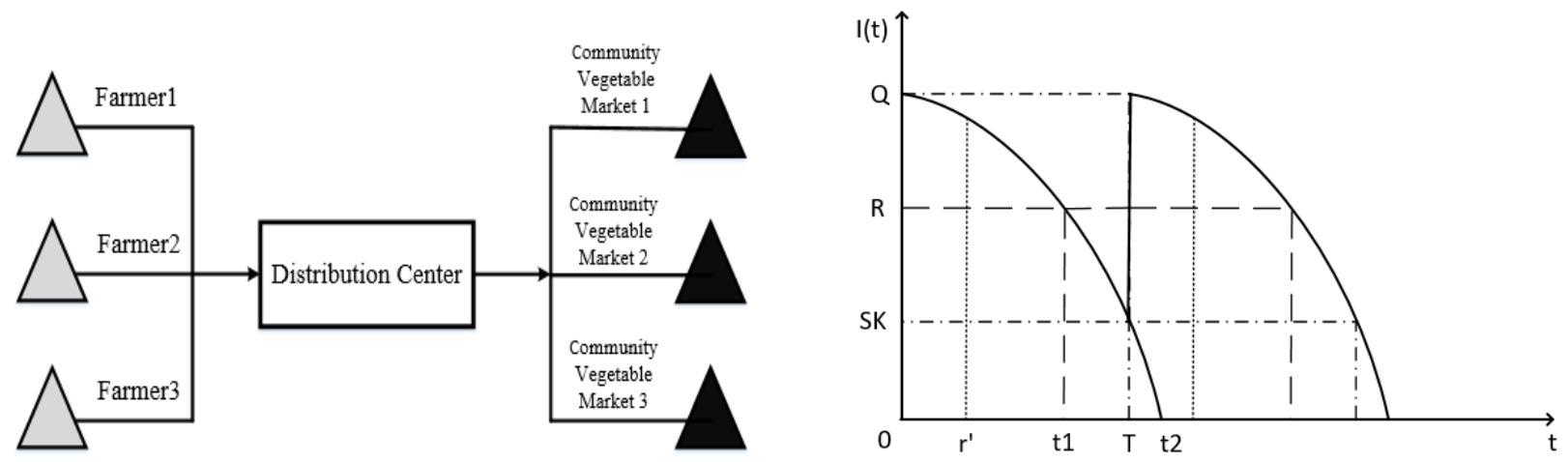

Fig.1 Fresh Agricultural Products Distribution Pattern Fig. 2 Change of fresh produce inventory in distribution center

\subsection{Fresh agricultural products distribution center inventory control model}

In order to simplify the model for easy research, the following assumptions are made for inventory. (1) The cold storage of the distribution center controls the inventory of the entire circulation mode and coordinates the upstream and downstream inventory activities. (2) Adopting (S, Q) inventory control strategy, an order application will be issued when the stock drops below the order point. (3) Only consider the situation of one fresh produce. (4) In order to ensure the normal supply of the community, a certain safety stock is set in the cold storage of the distribution center. Downstream inventory activities from a cold storage facility to a community vegetable market are not allowed to be out of stock. (5) As people's acceptance of the community food market increased and demand increased, the set demand rate was a linear function of time, with $D(t)=a t+b, a \geq 0, b>0$. (6) Fresh agricultural products are perishable items. To further suit the actual conditions, the deterioration rate $\theta(t)$ is variable. And the deterioration rate function $\theta(t)$ follows the three-parameter Weibull distribution ${ }^{[10]}$, the specific form of the distribution function and density function can be expressed as

$$
F(t)=1-e^{-\alpha(t-\gamma)^{\beta}}, \quad f(t)=\alpha \beta(t-\gamma)^{\beta-1} e^{-\alpha(t-\gamma)^{\beta}} .
$$

The deterioration rate can be expressed as: $\theta(t)=\frac{f(t)}{1-F(t)}=\alpha \beta(t-\gamma)^{\beta-1}$

Among them, the parameters $\alpha, \beta$ and $\gamma$ respectively represent the Weibull function scale factor, shape factor and position factor. Combining the characteristics of timely supply and freshness of fresh agricultural products, the parameter of the function $\theta(t)$ is set to satisfy $1<\beta<2$ and $\gamma>0$. It means that fresh produce does not degenerate when it just enters the cold storage of the distribution center, but it will only happen after a period of time. The various parameters are shown in Table.1.

Table.1 Symbols of related parameters of the inventory control model for fresh produce distribution centers

\begin{tabular}{clcl}
\hline Symbol & \multicolumn{1}{c}{ Explanation } & Symbol & \multicolumn{1}{c}{ Explanation } \\
\hline$T$ & Optimal order cycle for fresh produce & $Q$ & Maximum inventory \\
$D$ & Demand for fresh produce & $Q^{*}$ & Economic order quantity \\
$C_{0}$ & The unit value of fresh produce & $t_{1}$ & Fresh produce order point \\
$C_{1}$ & Single ordering cost of fresh produce & $t_{2}$ & The latest arrival time of fresh produce \\
$C_{2}$ & Cold storage cost per unit of time & $S K$ & Safety stock \\
\hline
\end{tabular}

From Fig. 2, we can see that at different timest, the main factors affecting the inventory level $I(t)$ are different. The following types are satisfied.

During the $\left(0, \gamma^{\prime}\right)$ time period, the product did not deteriorate, and the metamorphic rate was 0 . The inventory change during this period was only related to the demand consumption, namely: 


$$
\frac{d I(t)}{d t}=-D(t), 0<t \leq \gamma^{\prime}
$$

The inventory level at this time is: $I(t)=-\int D(t) d t=-\int(a t+b) d t=-\frac{a t^{2}}{2}-b t+A_{1}$

Boundary value is: $I(0)=Q$

Then the inventory level at time $\gamma^{\prime}$ is: $I\left(\gamma^{\prime}\right)=Q-\int_{0}^{\gamma^{\prime}}(a t+b) d t=Q-\frac{a \gamma^{\prime 2}}{2}-b \gamma^{\prime}$

During the $\left(\gamma^{\prime}, T\right)$ time period, the product begins to degenerate and its metamorphic rate is $\theta(t)$.

During this period, the inventory change level is related to the demand consumption and deterioration spoilage of the product, namely: $\frac{d I(t)}{d t}=-\theta(t)-D(t), \gamma^{\prime}<t \leq T$

The inventory level at this time is: $I(t)=\int[-\theta(t)-D(t)] d t=-\alpha(t-\gamma)^{\beta}-\frac{a t^{2}}{2}-b t+A_{2}$

Boundary value is: $I\left(t_{2}-T\right)=S K$

Due to the particularity of the community food market, the Cold Storage in the Distribution Center must ensure the continuous supply of fresh food required by community market every day. Can't wait for inventory to drop to zero then organizing orders. Therefore, we set an appropriate order point in the cold storage center. When the product inventory in the cold storage consumes below the point $R$, an order notification is issued, and the inventory is replenished in time, so that the cold storage inventory reaches the maximum inventory quantity $Q$. The time corresponding to the order point $R$ is the order lead time, denoted by $t_{1}$, with $\gamma^{\prime}<t_{1}<T$. In addition, in order to deal with the risk of the manufacturer's supply disruption caused by accidents, an appropriate safety stock should be set in the cold storage center. To guarantee the normal supply of fresh food in community markets and prevent out-of-stock occurrences.

Vertical (6) and (7) can be obtained: $A_{2}=S K+\alpha\left(t_{2}-T-\gamma\right)^{\beta}+\frac{a\left(t_{2}-T\right)^{2}}{2}+b\left(t_{2}-T\right)$

Then, the stock amount at time $t_{1}$ can be expressed as: $I\left(t_{1}\right)=-\alpha\left(t_{1}-\gamma\right)^{\beta} \frac{a t_{1}^{2}}{2}-b t_{1}+\alpha\left(t_{2}-T-\gamma\right)^{\beta}+\frac{a\left(t_{2}-T\right)^{2}}{2}+b\left(t_{2}-T\right)+S K$

The demand for the entire period $(0, T)$ is $\int_{0}^{T} D(t) d t=\int_{0}^{T}(a t+b) d t=\frac{a T^{2}}{2}+b T$. It can be concluded that the number of products that have deteriorated during this period is $Q^{*}-\frac{a T^{2}}{2}-b T$, and the perpetual deterioration loss fee is $C_{C_{1}}\left(Q^{*}-\frac{a T^{2}}{2}-b T\right)$.

During the $\left(T, t_{2}\right)$ time period, the safety stock is consumed. This is mainly because producers are short of goods or stocking, which results in delays in the distribution of fresh produce to the distribution center. The time $t_{2}$ represents the latest arrival time of the product, and $t_{2}-T$ is the manufacturer's maximum out-of-stock time. The level of inventory changes during this period is also related to the demand and deterioration of the product, namely: $\frac{d I(t)}{d t}=-\theta(t)-D(t), T<t \leq t_{2}$

The inventory level at this time is: $I(t)=\int[-\theta(t)-D(t)] d t=-\alpha(t-\gamma)^{\beta}-\frac{a t^{2}}{2}-b t+A_{3}$

Boundary value is: $I\left(t_{2}-T\right)=S K, I\left(t_{2}-t_{2}\right)=I(0)=0$

Vertical (8) and (9) can be obtained: $A_{3}=\alpha(-\gamma)^{\beta}$




$$
I\left(t_{2}-T\right)=-\alpha\left(t_{2}-T-\gamma\right)^{\beta}-\frac{a\left(t_{2}-T\right)^{2}}{2}-b\left(t_{2}-T\right)+\alpha(-\gamma)^{\beta}=S K
$$

From $\frac{d I(T)}{d t_{2}}=-\alpha \beta\left(t_{2}-T-\gamma\right)^{\beta-1}-a\left(t_{2}-T\right)-b=0$, can be get $t_{2}$ 。

To sum up, the total inventory cost of the cold storage in the distribution center includes ordering costs, storage costs, and deteriorating costs. Its formula is:

$$
T C=\left[C_{1}+\frac{1}{2} C_{2} Q^{*} T+C_{0}\left(Q^{*}-\int_{0}^{T}(a t+b) d t\right)\right] \times \frac{D}{Q^{*}}=\left[C_{1}+\frac{1}{2} C_{2} Q^{*} T+C_{0}\left(Q^{*}-\frac{a T^{2}}{2}-b T\right)\right] \times \frac{D}{Q^{*}}
$$

The objective function is mainly to find an optimal solution $\left(T^{*}, Q^{*}\right)$, so as to minimize the total cost.

Obviously, the necessary condition for $T C$ to take the minimum is: $\frac{\partial T C}{\partial T^{*}}=0, \frac{\partial T C}{\partial Q^{*}}=0$

Get the answer is: $T^{*}=\frac{C_{2} Q^{*}}{2 C_{0} a}-\frac{b}{a}, Q^{*}=\frac{\sqrt{8 C_{0} C_{1} a+4 C_{0}^{2} b^{2}}}{C_{2}}$

\section{Example Application}

To verify the applicability of the above models, the fresh agricultural products selected for analysis in this paper include: pork, lamb, beef, vegetables and fruits. The data such as single ordering cost, unit storage cost, and fresh food unit price are based on the valuation of the average price in the Beijing market. The final summary of effective data is shown in Table.2.

\begin{tabular}{|c|c|c|c|c|c|c|}
\hline Species & $\begin{array}{l}\text { Single ordering } \\
\text { cost } C_{1}(\mathrm{RMB})\end{array}$ & $\begin{array}{c}\text { Daily cold storage } \\
\text { costs } C_{2} \quad(\mathrm{RMB} / \mathrm{kg})\end{array}$ & $\begin{array}{l}\text { The unit } \\
\text { value } C_{0} \\
(\mathrm{RMB} / \mathrm{kg})\end{array}$ & $\alpha$ & $\beta$ & $\gamma$ \\
\hline Pork & 60 & 4.7 & 20.20 & 0.01 & 1.5 & 3 \\
\hline Beef and mutton & 60 & 4.7 & 24.85 & 0.01 & 1.5 & 3 \\
\hline Vegetables & 50 & 4.7 & 15.30 & 0.01 & 1.5 & 1 \\
\hline Fruits & 50 & 4.7 & 16.60 & 0.01 & 1.5 & 2 \\
\hline
\end{tabular}

Table.2 Basic information of fresh produce in Beijing

The data in Table. 2 is brought into the model formula and calculated by MATLAB, and the stock results of pork, beef, lamb, vegetables and fruits in the Beijing Fresh Produce Distribution Center can be obtained. See Table.3.

Table.3 Best Orders for Beijing Fresh Produce Distribution Center

\begin{tabular}{ccccccc}
\hline Species & $\begin{array}{c}\text { Maximum } \\
\text { inventory } Q \\
(\mathrm{~kg})\end{array}$ & $\begin{array}{c}\text { Economic } \\
\text { order } \\
\text { quantity } Q^{*} \\
(\mathrm{~kg})\end{array}$ & $\begin{array}{c}\text { Optimal } \\
\text { order } \\
\text { cycle } T \\
(\text { day })\end{array}$ & $\begin{array}{c}\text { Order } \\
\text { point } t_{1} \\
(\text { day) }\end{array}$ & $\begin{array}{c}\text { Safety } \\
\text { stock } S K \\
(\mathrm{~kg})\end{array}$ & $\begin{array}{c}\text { The latest } \\
\text { arrival time } t_{2} \\
(\text { day })\end{array}$ \\
\hline Pork & 206552.1 & 197735.4 & 1.53 & 0.77 & 8816.71 & 2.30 \\
Beef and mutton & 187021.0 & 179796.0 & 1.70 & 0.85 & 7225.04 & 2.55 \\
Vegetables & 676106.4 & 651106.4 & 1.00 & 0.50 & 25000.01 & 1.50 \\
Fruits & 731425.5 & 706425.5 & 1.00 & 0.50 & 25000.02 & 1.50 \\
\hline
\end{tabular}

It can be seen from the above calculation results. In the case of the smallest total inventory cost, the best ordering cycle for meat in the distribution center is more than 1.5 days, and the best ordering cycle for vegetables and fruits is 1 day. Among them, the best order quantity for pork was $197,735.4 \mathrm{~kg}$, beef and mutton was $179,796.0 \mathrm{~kg}$, vegetables were $651,106.4 \mathrm{~kg}$, and fruits were $706,425.5 \mathrm{~kg}$. Moreover, the latest arrival time of each fresh produce acceptable to the distribution center does not exceed three days. The shortest arrival time for vegetables and fruits is 1.5 days. Based on actual situation analysis data, fresh produce is perishable and not easily preserved. Coupled with the limited size of the community food market and the lack of necessary cold storage 
facilities, fresh produce sold on a daily basis are placed under normal temperature conditions and should not be stored overnight. In order to ensure the freshness and food safety of fresh produce, the distribution center needs to provide daily real-time supply to the community vegetable market and supplement its own inventory in time, so as to ensure that the fresh food has a surplus storage time at the consumer. Therefore, this model has a certain degree of correctness and feasibility. It can provide a scientific reference for optimizing the inventory of fresh produce distribution centers in Beijing.

\section{Conclusion}

Based on the background of farmer-community docking, this paper combines the characteristics of perishable fresh produce in the circulation mode of farmer-distribution center-community vegetable market, and constructs an inventory control model for fresh produce in the collection center. And use MATLAB software programming calculations corresponding examples. The results show that the model can determine the optimal ordering cycle and optimal order quantity for each fresh produce in the distribution center according to the actual market conditions with the lowest total inventory cost, which has certain accuracy and feasibility. Moreover, the application of the model can effectively coordinate the production, inventory, and sales of fresh agricultural products in the upstream and downstream (Farmers and Community Markets), and can improve the circulation efficiency of fresh produce in Beijing to a certain extent, and reduce the loss of agricultural products.

There are still some deficiencies in the establishment of the model. First, the simplified model does not take into account the out-of-stock condition of the community market and the cost of loss caused by the shortage of goods. Second, the system model ignores the effect of out-of-stock frequency on social satisfaction. This is because if the shortage time is short, the missing food can be immediately filled and it will not have a significant impact on its supply.

\section{REFERENCES}

[1] SUN Y J. Global stabilizability of uncertain systems with time-varying delays via dynamic observer-based output feedback[J]. Linear Algebra Appl, 2002, 353:91-105.

[2] DONE Y, LIU J, MEI S. Stabilization for switched nonlinear time-delay systems[J]. Nonlinear Analysis: Hybrid Systems, 2011, 5:78-88.

[3] OLSSON F. Modelling Two-echelon Serial Inventory Systems With Perishable Items[J]. A Journal of Management Mathematics, 2010, 21(01):1-17.

[4] Li Xiang, Dong Jieshuang, Liu Weiwei. The Vensim Simulation Model of Supplires and Disteibutors' Deteriorating Items[J]. Logistics Sci-Tech, 2016(11):140-144.

[5] Li Changbing, He Yahui, Yang Yu. Research on Safety Inventory Optimization of Multi-echelon Distribution in Cold Chain Logistics[J]. Hubei Agricultural Sciences, 2015(20):5136-5139.

[6] Wang Shuyun, Jiang Yingmei, Wang Xianjie. Research on Three-echelon Integrated Cold Chain Inventory Model for Agro-food[J]. Chinese Journal of Management Science, 2016(02):108-114.

[7] Ran wenxue, Liu huijuan. Fresh Agricultural Integrated Inventory Cost Control Based on the Multi-echelon Supply Chain[J]. Logistics Engineering and Management, 2016(11):78-83.

[8] Hou Guodong, Sun Xiao, Wang Shuyun, Jiang Yingmei. Study on Supply Chain Coordination Mechanism Based on Fresh Food Inventory Model[J]. Journal of Commercial Economics, 2017(05):29-31. 
[9] Deng Qi. The Ordering Strategy of Fresh Agricultural Products Based on Deterioration and Loss[J].Statistics \& Decision,2013(06):41-44.

[10]Wang Daoping, Yu Jundi. An Inventory Model for Deteriorating Items with Weibull Distribution[J]. Chinese Journal of Management Science,2010(18):436-440.

[11]Han Shuguang, Xia Peng. Study of Fresh Agricultural Products Ordering Policy Based on Deteriorating Inventory Theoty[J]. Journal of Zhejiang Sci-Tech University(Social Sciences Edition), 2016(06):532-536. 